\title{
Estimation of composition change in pulsed Nd:YAG laser welding
}

\author{
M. J. Torkamany ${ }^{1}$, P. Parvin ${ }^{2}$, M. Jandaghi ${ }^{2}$ and J. Sabbaghzadeh ${ }^{1}$ \\ ${ }^{1}$ Iranian National Center for Laser Science \& Technology, P.O .Box 14665-576, Tehran, \\ Iran \\ 2 Physics Department, Amir Kabir university of technology,P.O.Box15875-4413, Tehran,
} Iran

\begin{abstract}
A numerical model based on the kinetic theory of gases and the thermodynamic laws is developed for keyhole formation in pulsed laser welding. For a single incoming pulse the spatial profile of the created keyhole was simulated as a function of time using this model. Since undesirable loss of the volatile elements affects on the weld metal composition and properties we have focused in our model to find the process conditions that minimum of these losses take place during pulsed laser welding. The major laser welding process parameters including pulse properties have been examined formerly in this model. The power density and pulse duration were the main investigated variables. The model predicts that loss of alloying elements increase at higher peak powers and longer pulse durations. The model was used for two different kinds of metals, one from the ferrous compounds Stainless Steel 316- and the other an aluminum alloy- 5754 Aluminum alloy-. By running the model for SS316 it was found that concentrations of the Fe base and Nickel were increased in the weld metal region while concentrations of the chromium and manganese were decreased. Pulsed laser welding of stainless steel 316 in keyhole mode was experimentally studied too. The welding work piece was $2 \mathrm{~mm}$ thick SS316 sheet metal. After welding experiments, samples were cut and weld cross sections were analyzed. The concentrations of iron, chromium, nickel and manganese were determined in the weld pool by means of the Proton-Induced X-ray Emission (PIXE) and Energy Dispersive X-ray/Wavelength Dispersive X-ray (EDX/WDX) analysis. It was shown that the composition alteration, predicted by the model due to varying of the laser parameters is in well accordance to the corresponding experimental data.

Al5754 was the second material used for laser welding experiments. Weld metal composition change of this alloy in keyhole mode welding, using a long pulsed Nd:YAG laser was investigated by use of the developed numerical model and supported with experimental measurements. During laser welding process, the significant variables were laser pulse duration and power density. It was predicted in the model and concurred experimentally that, the concentration of magnesium in the weld metal decreases by increasing the laser pulse duration, while the aluminum concentration increases. Moreover, the concentrations of aluminum and magnesium elements, in the weld metal were
\end{abstract}


determined by laser induced breakdown spectroscopy (LIBS) for different welding conditions.

Keywords: Pulsed laser welding, Nd:YAG Laser, Alloying element losses, Keyhole formation model, Stainless Steel 316, Aluminum alloy 5754, LIBS

\section{Introduction}

During laser beam welding of many important alloys, vaporization usually takes place from the weld pool surface. Undesirable vaporization of volatile alloying elements changes the weld metal composition relative to the base metal and resultantly the mechanical and metallurgical properties of the weld metal will change too. To realize a quantitative estimation of the weld metal composition, while varying the irradiation parameters, a comprehensive model is required. Several authors have used Longmuir equation for the calculation of the changes in weld metal composition due to various welding processes $[1,2]$.The equation is useful for calculation of relative vaporization rates from different alloying elements in vacuum and it results to a higher absolute rate than actual values[2-5]. Mundra and T.Debroy [2] derived equations for the vaporization rate of various alloying elements in conduction mode laser welding of high-manganese stainless steel with a CW $\mathrm{CO}_{2}$ laser. The model is based on the coupling of the principles of weld pool transport phenomena and vapor phase gas dynamics. In a similar work developed by X.He and T.Debroy [5] the composition changes of stainless steel were estimated during Nd: YAG laser welding. Although these models are valid for conduction mode welding but, when the laser power density is increased to a level sufficient to evaporate a thin layer of material and the second kind of laser welding mode known as keyhole welding occurs they are not able to evaluate the composition change. By keyhole formation, a deep hole is created inside the weld pool, which is an effective trap for the laser beam [6]. Therefore, creation of keyhole will increase the laser energy coupling to the material. U. Dilthey and co-workers [7] developed a theoretical model based on the diffusion equation to evaluate the composition change of aluminum alloy during laser welding with a continuous wave (CW) $\mathrm{CO}_{2}$ source. They suggested a quasi-stationary model and considered keyhole as a cylinder, with an invariable radius and depth.

In order to obtain a quantitative understanding of composition change in keyhole welding with pulsed lasers, it is necessary to propose a model that predicts the keyhole formation as well as the corresponding physical phenomena that occurs.

In this work, at first the vaporization rates of SS316 alloying elements such as $\mathrm{Fe}, \mathrm{Ni}, \mathrm{Mn}$ and $\mathrm{Cr}$ were determined through a theoretical model based on keyhole welding with pulsed Nd:YAG laser. The influences of laser pulse energy and duration on the composition change of the weld metals were predicted by model and compared with the experimental results obtained from WDX analysis.

Secondly, a LIBS (Laser Induced Breakdown Spectroscopy) analysis as a technique of atomic emission spectroscopy (AES) was used in this work to measure the composition change of the weld metal. The purpose is to determine the elemental composition of the sample. LIBS performs real time composition analysis that can be very superficial. Laser-induced breakdown spectroscopy (LIBS), also sometimes called Laser-induced plasma spectroscopy 
(LIPS) has developed rapidly as an analytical technique over the past two decades. The technique employs a low-energy pulsed laser (typically ten to hundreds of mJ per pulse) and a focusing lens to generate plasma that vaporizes a small amount of a sample. A portion of the plasma light is collected and a spectrometer disperses the light emitted by excited atomic and ionic species in the plasma, a detector records the emission signals, and electronics take over to digitize and display the results. The spectra emitted are used to determine the sample's elemental constituents [8]. The analysis is ranging from a simple identification of the atomic constituents to a more detailed determination of relative concentrations or absolute masses [8-13]. LIBS technique is regarded as a superior elemental analysis method including simultaneous multi-element detection capability. In addition, because the laser spark uses focused optical radiation rather than a physical device such as a pair of electrodes to form the plasma, LIBS has several advantages compared with conventional AES-based analytical methods. These advantages are simplicity, rapid and real-time analysis, no need for sample preparation, allowing in situ analysis, detection ability of gaseous samples, as well as liquids and solids, and good sensitivity for halogen elements difficult to monitor with other methods [8,9]. In general, several solid state lasers and in particular, Q-switched Nd:YAG lasers with nanosecond duration are typically used for LIBS measurements. Other types of lasers, most notably the pulsed CO2 laser and the UV excimer lasers have been also employed for LIBS exposure [9].

Here, the composition change of the weld metal due to long pulsed Nd:YAG laser welding of Al5754 alloy was studied using the LIBS method based on ArF excimer laser exposure, in order to determine the trace of element loss in the weld metal after welding process.

\section{Keyhole Formation Model}

There are several models for prediction of keyhole shape during laser welding [14-16]. The fundamentals of the present model are principally similar to the model that was developed by Semak [16]. Accordingly, in the speeds lower than $1 \mathrm{~cm} / \mathrm{s}$ the profile of keyhole is assumed symmetrical, co-axial with the laser beam. Moreover, keyhole is held open due to balance of the surface tension and the (recoil) ablation pressures. At high speed, keyhole axis is deviated from beam axis such that the recoil pressure exceeds the surface tension, whereby the keyhole wall moves inside the weld pool with velocity equal to summation of the evaporation and melt expulsion velocities $[16,17]$.

In this work, welding process speed is chosen to be $0.5 \mathrm{~cm} / \mathrm{s}$, therefore the keyhole's shape remain be symmetrical and co-axial with the laser beam. The melt expulsion velocity is negligible due to balance in surface tension and recoil pressures. Because of the melt flow and presence of Marangoni effect, the effective thermal conductivity is assumed twice the stationary melt conductivity $[18,19,20]$.

For the case of a Gaussian intensity distribution of the incident laser beam, the value of the local absorbed intensity $I_{a b s}$ (i) for each point of the keyhole surface is given by the [16,21]:

$$
I_{a b s}(i)=A_{0} \cos ^{q+1}(a(i))\left(I_{0} \exp \left(\frac{-x(i)^{2}}{r_{l}^{2}}\right) \exp (-\alpha y(i))\right)
$$

Where $I_{0}$ is laser intensity at the beam axis, and q denote a modification factor to obtain an angular dependence close to the typical experimental curve that depended on the metal. The 
parameter $A_{0}=0.27$ ascertains the absorption coefficient for normal incidence in boiling temperature of SS316, the x-axis is parallel to the metal surface, and the y-axis coincides with the beam axis. The $\mathrm{i}$ quantity refers to the point number on the keyhole surface, a(i) represent to the angle made by beam and keyhole surface vector (see figure1) and $\alpha$ is the inverse Bremsstrahlung absorption coefficient that can be calculated from the following equation[17]:

$$
\alpha\left(m^{-1}\right)=\frac{n_{e} n_{i} Z^{2} e^{6} g}{6 \sqrt{3} m \varepsilon_{0}^{3} \omega^{2}(2 \pi)^{1 / 2}} \frac{1}{\left(m_{e} k T_{e}\right)^{3 / 2}}
$$

Where $\mathrm{Z}$ is the average ionic charge in the plasma, $\mathrm{c}$ is the speed of light, $m_{e}$ is the electron mass, $\omega$ is the angular frequency, $\varepsilon_{0}$ is the permittivity of free space, $n_{i}$ is the ion density, $n_{e}$ is the electron density, and $\mathrm{g}$ is the mechanical Gaunt factor. Where $n_{e}$ and $T_{e}$ are the electron density and temperature of welding plasma respectively. These parameters have been measured for Nd:YAG pulsed laser welding by J. Sabbaghzadeh and his co-workers [22]

Figure1 illustrates the schemes of curve interaction with keyhole surface and the corresponding velocity components.

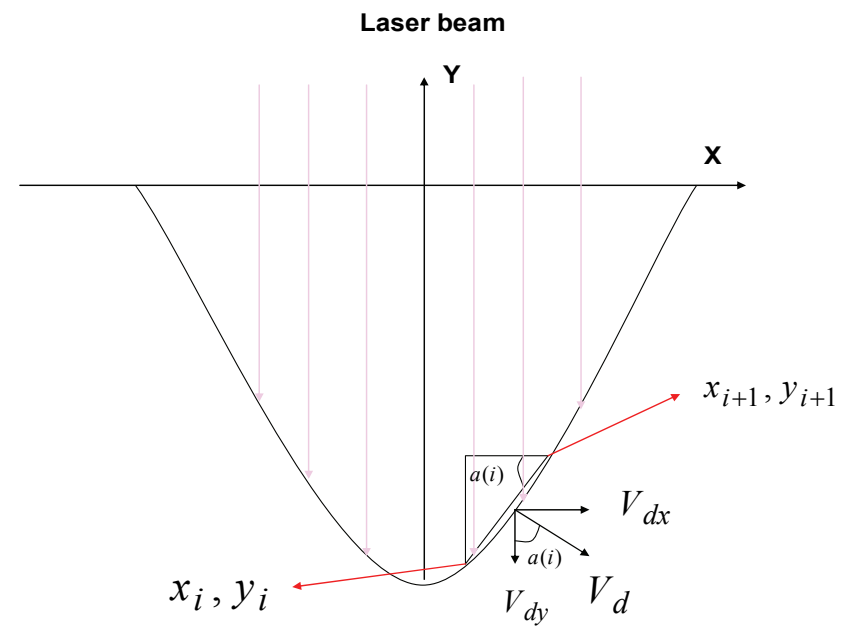

Fig. 1. Schematic illustration of laser interaction with keyhole surface and the corresponding velocity components.

The local energy flux balance can be shown by:

$$
I_{a b s}=-k \nabla_{n} T+\rho_{m} L_{v} V_{d v}
$$

Where $\mathrm{k}$ is the heat conductivity, and $L_{v}$ is the latent heat of vaporization and $\rho_{m}$ is melted metal density. Temperature gradient on the right-hand side of equation (3) can be estimated to be [16] 


$$
-\nabla_{n} T=\frac{T_{s}-T_{m}}{\frac{a}{u}}
$$

Where $\mathrm{a}, \mathrm{u}, \mathrm{T}_{\mathrm{s}}$ and $\mathrm{T}_{\mathrm{m}}$ are heat diffusivity, laser beam translation speed, boiling and melting temperatures respectively.

Substituting equations (1) and (4) in to equation (3) ,the evaporation velocity of the ith point on the keyhole surface is given by:

$$
V_{d v}(i)=\left[\frac{A_{0} \cos ^{q+1}(a(i))\left(I_{0} \exp \left(\frac{-x(i)^{2}}{r_{I}^{2}}\right) \exp (-\alpha y(i))\right)-\left(T_{s}-T_{m}\right) \frac{u k}{a}}{\rho_{m} L_{v}}\right]
$$

Variation of the melt thickness is depended on the mass source and sinks due to melting and evaporation and expulsion velocies $[16,23]$. Change of the melt layer can be shown by following equation:

$$
\frac{\partial b}{b t}+V_{e}=-V_{d v}+V_{m}
$$

Where $V_{e}, V_{m}, V_{d v}$ are the expulsion, melting and evaporation velocities respectively and $\mathrm{b}$ denotes the melt layer thickness. As mentioned above we assume that $V_{e}$ equals to zero because of negligible process speed, thus variation of the melt thickness is due to the melting and evaporation events.

Since the weld pool profile is strongly affected by the pattern of fluid flow in the weld pool, the convection is significant. There are four different driving forces in the molten weld pool during laser welding causing to convection phenomenon, which affects the pool's shape. These forces are 1-buoyancy or gravity force, 2-surface tension gradient force or Marangoni force, 3-electromagnetic, electromotive force (emf) or Lorentz force and 4-impining or friction force. Lorentz force is absent for gas and laser beam welding [19]. In the weld pool, temperature difference induces a variation in density, thus, the molten metal in the pool boundary is cooler and denser than that on near the center of the weld pool which sinks under the force of gravity. Where as oppositely the molten metal near the center of weld pool is displaced and rise. The circulated velocity is created by gravity force about $1 \mathrm{~cm} / \mathrm{s}$. The impinging force is the result of momentum transfer through friction between impinging particles and metal atoms in the molten weld pool. This force induces convection velocity about $1-10 \mathrm{~cm} / \mathrm{s}$ [24]

Surface tension of liquid depends on the temperature of that liquid. So a temperature gradient causes to a gradient in surface tension. This gradient exerts a force $\left(F_{\sigma}\right)$ given by:

$$
F_{\sigma}=-\frac{d \sigma}{d T} \nabla T
$$

Where $\sigma$ indicate the surface tension of the molten metal, $\mathrm{T}$ is temperature, and $\nabla T$ is the temperature gradient at the weld pool surface. In commonly used welding conditions Surface tension gradients induce strong circulation at rates from $10-100 \mathrm{~cm} / \mathrm{s}$ from the hotter, lower surface tension liquid at the center of the weld pool to the cooler, higher surface tension liquid at the pool edges [18] (figure 2). Finally a dominant Marangoni force 
is suggested, which results in a wider and shallower weld pool than previous one without the convection.

The Marangoni effect is taken in to account by a simple solution that is considering an artificially higher thermal conductivity for the material in the presence of convection. Effective thermal conductivity in the presence of Marangoni flow is assumed to be at least twice the stationary melt conductivity $[18,19,20]$.

An arbitrary shape of the keyhole wall was assumed in order to start generating the actual keyhole.

The melt thickness is also presumed to be constant during the formation of keyhole. On the other hand, the melting front also moves together with the keyhole wall and a new portion of the metal is melted to replace the evaporation melt, Thus, $\mathrm{b}$ is taken to be constant such that $V_{m}=V_{d v}=V_{d}$

Where $V_{d}$ refers to the velocity of the keyhole wall. It is perpendicular to the keyhole surface and its components are given by [16]:

Where

$$
V_{d x}(i)=\sin (a(i)) V_{d}(i)
$$

$$
\begin{gathered}
V_{d y}(i)=-\cos (a(i)) V_{d}(i) \\
\sin (a(i))=\frac{y(i+1)-y(i)}{\left[(x(i+1)-x(i))^{2}+(y(i+1)-y(i))^{2}\right]^{\frac{1}{2}}}
\end{gathered}
$$

$$
\cos (a(i))=\frac{x(i+1)-x(i)}{\left[(x(i+1)-x(i))^{2}+(y(i+1)-y(i))^{2}\right]^{\frac{1}{2}}}
$$

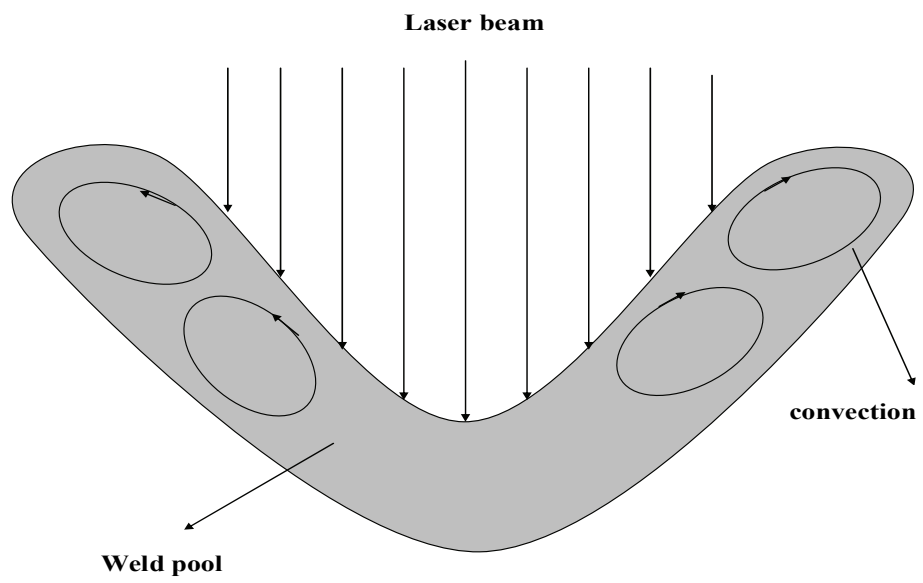

Fig. 2. Marangoni effect inside the weld pool and keyhole pattern.

Subsequently, the change in the position of the ith point on the keyhole surface can be determined as below 


$$
\begin{aligned}
& x_{\text {new }}=x(i)+V_{d x}(i) \Delta t \\
& y_{\text {new }}=y(i)+V_{d y}(i) \Delta t
\end{aligned}
$$

Where $\mathrm{x}_{\text {new }}(\mathrm{i})$ and $\mathrm{y}_{\text {new }}(\mathrm{i})$ are new coordinates after the time interval $\Delta t$. The time interval $\Delta t$ is selected as nearly $1 / 1000$ of pulse duration. Components of the velocity are shown in figure 1 .

The results of first stage of the model containing the shape and depth of the created keyhole for each set of processing parameters was used for the next step of model (vaporization of alloying elements). The computed surface and volume of the keyhole as a function of time are used to determine the vaporization rate as well as the composition change of alloying elements. Results of calculated penetration depth of keyhole are compared with the results obtained from experimental weld profiles of SS316 in figure 3. The thermo physical properties of metal used in the model are presented summarized in table 1.

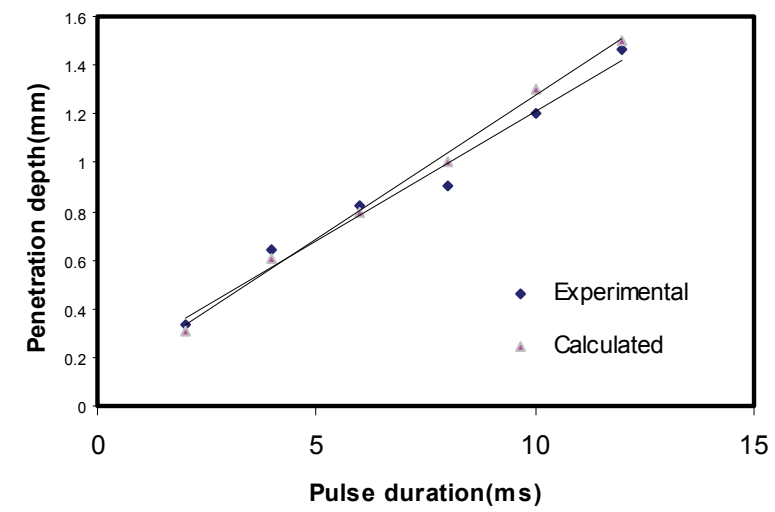

Fig. 3.The calculated penetration depth and the measured penetration for various durations of laser pulses.

\begin{tabular}{ll}
\multicolumn{1}{c}{ PROPERTY } & \multicolumn{1}{c}{ VALUE } \\
\hline Density $\left(\mathrm{kg} / \mathrm{m}^{3}\right)$ & 7200 \\
Melting point $(\mathrm{K})$ & 1727 \\
Boiling point $(\mathrm{K})$ & 3100 \\
Thermal conductivity of solid $\mathrm{W} / \mathrm{mK}$ & 29 \\
Effective viscosity $\left(\mathrm{kg} / \mathrm{m}^{5}\right)$ & 0.1 \\
Ratio of specific heats of vapor $\gamma_{v}$ & 1.667 \\
Beam radius $(\mu \mathrm{m})$ & 200 \\
Heat of evaporation of $(\mathrm{J} / \mathrm{kg})$ & $6.52 E 6$ \\
\end{tabular}

Table 1. SS316 Data used for the calculation of vaporization rate and the composition change. 


\section{Vaporization of Alloying Elements}

Vaporization of the alloying element is due to the difference in partial vapor pressure and concentration gradient of each component. The materials vaporization mainly takes place at the keyhole inner wall sheath [2-4].

Pressure and concentration of alloying elements are higher near the weld pool surface in the Knudsen layer than in the bulk shielding gas and in the keyhole bulk (In fact, the pressure of the vapor inside the keyhole is close to the ambient pressure [23]). Partial pressure of each alloying element in the Knudsen layer is related to equilibrium temperature of this layer and can be calculated using the following equation [25]:

$$
\log _{10}(p)=A+\frac{B}{T}+C \log _{10}^{T}+D T+E T^{2}
$$

Where A, B, C, D, and E are constant coefficients which usually differs for the various elements, and $\mathrm{T}$ refers to the temperature. For the main elements of table 1 i.e/, $\mathrm{Fe}, \mathrm{Mn}, \mathrm{Ni}$, and $\mathrm{Cr}$, the corresponding coefficients are listed in table 2 [25].

\begin{tabular}{|l|l|l|l|l|l|}
\hline & $\mathrm{A}$ & $\mathrm{B}$ & $\mathrm{C}$ & $\mathrm{D}$ & $\mathrm{E}$ \\
\hline $\mathrm{Fe}$ & 11.55 & -19538 & -.6254 & $-27 E 9$ & $1908 E-13$ \\
\hline $\mathrm{Mn}$ & -123.9 & -5984 & 47.07 & -.014 & $1.5 E-4$ \\
\hline $\mathrm{Cr}$ & -87.07 & -3505 & 33.65 & -.929 & $8.3 E-7$ \\
\hline $\mathrm{Ni}$ & -214.3 & -3519 & 74.94 & -.018 & $15.1 E-7$ \\
\hline
\end{tabular}

Table 2. Constant coefficients for calculation of equilibrium vapor pressure of various alloying elements of SS-316.

Figure 4 illustrates the equilibrium vapor pressure (atm) as a function of temperature (k).

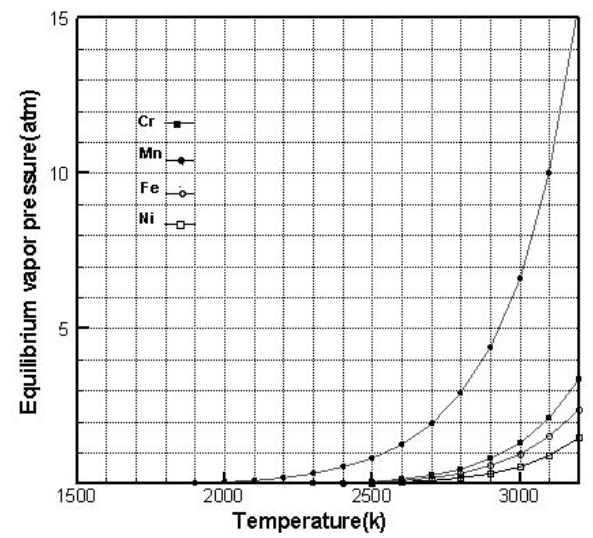

Fig. 4. Equilibrium vapor pressure (atm) of different constituents of SS316 as a function of temperature $(\mathrm{K})$. 
Total vapor pressure at the weld pool surface (Knudsen layer) is obtained from summation of the equilibrium vapor pressure of various alloying elements.

$$
P_{L}=\sum_{i} a_{i} P_{i}^{0}
$$

Where $a_{i}$ and $P_{i}^{0}$ are the activity and equilibrium vapor pressure of the alloying element $\mathrm{i}$ respectively where as i refers to the number of alloying elements.

It is suggested that Knudsen layer is filled only with metal vapor and no shielding gas attends inside. The calculated pressure of the Knudsen layer is subsequently used to obtain the loss of each alloying element due to concentration and pressure gradient vaporization rates.

\subsection{Vaporization due to concentration gradient}

The vaporization flux due to concentration gradient can be predicted from the kinetic theory of gases $[2-5,26]$ :

$$
J_{c, i}=K_{g, i} M_{i} \frac{\left(a_{i} P_{i}^{0}-P_{i, g}\right)}{R T_{e}}
$$

Where $J_{c, i}$ is the vaporization flux of element i due to concentration gradient, $P_{i, g}$ is vapor pressure of the alloying element $\mathrm{i}$ in the keyhole, $M_{i}$ denotes the molecular weight of the element $\mathrm{i}, \mathrm{R}$ represents gas constant and $K_{g, i}$ ascertains the mass transfer coefficient of element $i$. In addition the mass transfer coefficient of element $i$ between the weld pool surface and the shielding gas, outside the keyhole is calculated from the graphical results of Schlunder and Gniclinski for a jet impinging on a flat surface and can be expressed by: [2-5]

$$
K_{g, i}=\frac{2 S c^{0.42} \mathrm{Re}^{0.5} D_{g, i}}{d}\left(1+\frac{\mathrm{Re}^{0.55}}{200}\right)^{0.5}\left[0.483-0.108 \frac{r}{d}+7.71 \times 10^{-3}\left(\frac{r}{d}\right)^{2}\right]
$$

Where $d$ is the diameter of the shielding gas nozzle(Figure 5), $r$ is the radial distance on the weld pool surface, $D_{g, i}$ denotes the diffusivity of the element in shielding gas in $\frac{m^{2}}{\mathrm{~s}}$ (see appendix), Re represents the Reynolds number at the nozzle exit and Sh ascertains the Schmit number of the element.

Mass transfer coefficient inside the keyhole is given by:

$$
K_{g, i}=\frac{\left(0.023 \operatorname{Re}^{0.83} S c^{1 / 3}\right) D_{i, g}}{D}
$$

Where D is mean diameter of the keyhole. Gilliand and Sherwood derived equation (19) for mass transfer between the liquid that flows on the wall of the pipe and the gas current that flows inside the pipe [27]. 
The longitudinal velocity of the vapor flow inside the keyhole is derived to determine the Schmit number in the keyhole through the following equation [7]:

$$
V_{Z}=\left(\frac{R T}{A} \frac{2 \sigma}{P_{a} a}\right)^{0.5}\left(1+\frac{2(H-Z)}{\sqrt{\pi} a}\right)^{-1}
$$

Where $\mathrm{Z}$ coordinate origin is taken from the keyhole bottom, A, $P_{a}$, a and $\sigma$ are atom mass of the admixture, external pressure, mean radius and coefficient of surface tension respectively. Mean velocity was written as :

$$
<V>=\frac{\int_{0}^{H} V_{z} d z}{H}
$$

Were $\mathrm{H}$ is keyhole depth.
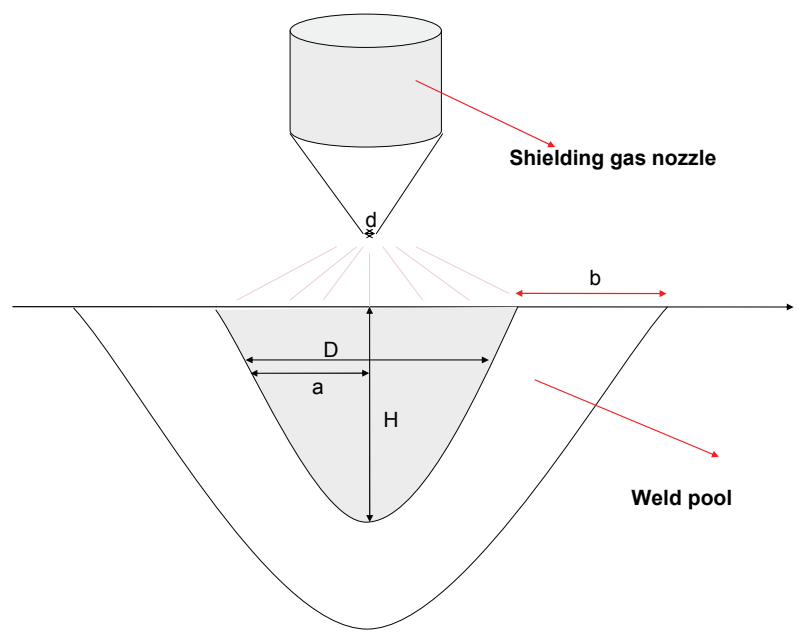

Fig. 5. Schematic illustration of keyhole's geometry and shielding gas nozzle

\subsection{Vaporization due to pressure gradient}

The vaporization flux due to pressure gradient at the weld pool surface corresponding to a local surface temperature $T_{s}$ (boiling temperature) is given by [2-5]:

$$
J_{P}=\rho_{v} u_{n}
$$

Where $u_{n}$ and $\rho_{v}$ are the mean velocity of particles and density of the vapor at edge of the Knudsen layer. According to kinetic theory of gases the mean velocity of particles can be calculated by equation: 


$$
u_{n}=M . s
$$

Where $\mathrm{M}$ is the Mach number and $\mathrm{s}$ is the propagation speed of sound in the gas.

Knudsen layer provokes a rapid change in the density and temperature of the vapor state by its treatment as a gas dynamic discontinuity. In fact, temperature, density, pressure and mean velocity of vapor at the edge of the Knudsen layer can be related to such quantities of vapor on the liquid surface $[2-5,28]$. The variations in quantities throughout the Knudsen layer are given by:

$$
\begin{gathered}
\frac{T_{v}}{T_{s}}=\left(\sqrt{1+\pi\left(\frac{\gamma_{v}-1}{\gamma_{v}+1} \frac{m}{2}\right)^{2}}-\sqrt{\pi} \frac{\gamma_{\nu}-1}{\gamma_{v}+1} \frac{m}{2}\right)^{2} \\
\frac{\rho_{v}}{\rho_{s}}=\sqrt{\frac{T_{s}}{T_{v}}}\left(\left(m^{2}+\frac{1}{2}\right) \exp \left(m^{2}\right) \operatorname{erfc}(m)-\frac{m}{\sqrt{\pi}}\right) \\
+\frac{1}{2} \frac{T_{s}}{T_{v}}\left(1-\sqrt{\pi} m \exp \left(m^{2}\right) \operatorname{erfc}(m)\right)
\end{gathered}
$$

Where $m=M \sqrt{\frac{\gamma_{\nu}}{2}}$ and $\gamma_{v}$ is the ratio of specific heat of vapor which is treated as a monoatomic gas, $T_{v}, \rho_{v}, T_{s}, \rho_{s}$ are temperature and density at the edge of Knudsen layer as well as the temperature and density of the vapor at the liquid surface respectively.

The Mach number is also determined in order to obtain $T_{v}$ and $\rho_{v}$. In this model the Mach number is derived from the pressure balance and the mechanical stability of the keyhole. The main forces acting on the keyhole wall are assumed to be the ablation pressure opposed by the surface tension forces. The ablation pressure is given in terms of the density at the edge of the Knudsen layer and the square of the ejected gas mean velocity through equation such that:

$$
P_{a b l}=m_{F e} \rho_{v} u_{n}^{2}
$$

Figure 6 shows the values of the Mach number versus laser power for different welding speeds.

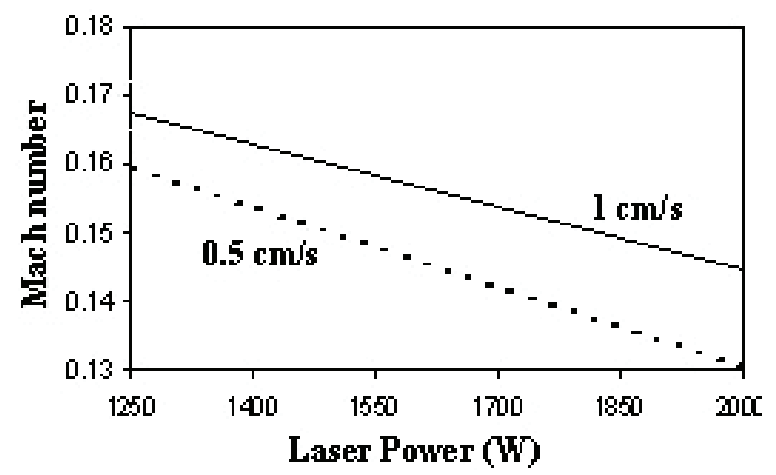

Figure6. Values of the Mach number versus laser power for different welding speeds, a focused Gaussian beam was used with radius $0.2 \mathrm{~mm}$ on stainless steel 316 . 
As a result, by increasing the welding speed, the keyhole becomes narrower and surface tension forces arise at the keyhole boundary, thus ablation pressure must increase in order to fulfill pressure balance. Therefore, the mean velocity of the ejected gas at the edge of the Knudsen layer enhances according to eq (25). Thus, regarding eq (22), the Mach number at higher speeds is grater for same laser power.

Vaporization flux due to pressure gradient of an alloying element, $J_{p, i},[2-5]$ is given by:

$$
J_{P, i}=a_{i} \frac{P_{i}^{0}}{P_{L}} \frac{M_{i}}{M_{v}} J_{P}
$$

Where $M_{v}$ is the mean molecular weight of the vapor species in the Knudsen layer that is given by:

$$
M_{v}=\sum_{i>1}^{n} M_{i} \frac{a_{i} P_{i}^{0}}{P_{L}}
$$

Therefore, the total vaporization flux, $J_{\text {total }, i}$, for an element $\mathrm{i}$ is given by:

$$
J_{\text {total }, i}=J_{P, i}+J_{C, i}
$$

If the surface and volume of the weld pool (keyhole profile) are known as functions of time, the total rate of vaporization and the vaporization rate of each alloying element can be obtained using $J_{\text {total }, i}$. The vaporization rate of element i, $G_{i}$ is found by integrating the vapor flux over the entire weld pool surface, and the total vaporization rate of all of elements, $G$, is given by:

$$
G=\sum_{i=1}^{n} G_{i}=\sum_{i=1}^{n} \iint_{S} J_{\text {total }} d x d y
$$

Where s refers to the weld pool surface. The weight percent of an element $\mathrm{i},(W t \%)_{t, i}$ as function of time is given by:

$$
(W t \%)_{t, i}=\frac{W_{i}-G_{i} t}{W-G t}
$$

Where $\mathrm{W}$ and $W_{i}$ are total mass of the weld metal and mass of species $\mathrm{i}$ in the weld metal respectively and $t$ represents time.

\section{Laser welding of SS316}

\subsection{Experimental setup}

A long pulsed Nd: YAG laser Model IQL-10 with mean power of $400 \mathrm{~W}$ and standard square shape pulse is chosen as the welding laser source to carry out the experiments. The pulse energy of laser was varied from 3 to 18 joules while the pulse duration could be changed from 2 to $12 \mathrm{~ms}$ as well. The process speed $(5 \mathrm{~mm} / \mathrm{s})$ and the pulse repetition rate 
(20 HZ) were kept to be invariant during the experiment. Model LA300W-LP Ophir joule meter is used to measure the pulse energies. A focusing optical system composed of three lenses is used with $75 \mathrm{~mm}$ focal length and $200 \mu \mathrm{m}$ minimum spot size. The welding work piece was a $2 \mathrm{~mm}$ thick SS316 sheet metal such that the corresponding chemical composition is presented in table 3. $10 \mathrm{lit} / \mathrm{min}$ flow of pure Ar gas, blowing from a coaxial nozzle was employed to shield the welded area against the oxidation.

At first, several set of SS316 samples $3 \mathrm{~cm} \times 3 \mathrm{~cm}$ were cut and the welding process was done using laser pulses with $1500 \mathrm{~W}$ peak power and 2-12 ms duration. Subsequently, the samples were prepared for the transverse cross section analysis. The samples were etched with a composition of $\mathrm{HCL}, \mathrm{HCOOH}$ and $\mathrm{HNO}_{3}$ to develop the weld region. After welding, EDX/WDX and PIXE analysis were performed to study the constituents of the weld metal. Under the same irradiation conditions, the EDX/WDX analysis were carried out using 10 individual points, on the transverse cross section of the weld metal for each sample to determine the concentration of the alloying elements.

\begin{tabular}{|l|ccccccccccc|}
\hline Element & $\mathrm{C}$ & $\mathrm{Mn}$ & $\mathrm{Cr}$ & $\mathrm{Ni}$ & $\mathrm{Si}$ & $\mathrm{MO}$ & $\mathrm{P}$ & $\mathrm{S}$ & $\mathrm{Al}$ & $\mathrm{Co}$ & $\mathrm{Cu}$ \\
& $\mathrm{Nb}$ & $\mathrm{Ti}$ & $\mathrm{V}$ & $\mathrm{Fe}$ & & & & & & & \\
\hline $\boldsymbol{W} \boldsymbol{t} \%$ & .05 & 1.27 & 18.1 & 8.04 & .49 & .33 & .02 & .003 & .003 & .13 & .32 \\
& .02 & .002 & .05 & balance & & & & & & & \\
\hline
\end{tabular}

Table 3. Constituents of 316 stainless steel.

\subsection{Comparison of theoretical and experimental results}

Average and standard deviation of each set of data was taken for statistical analysis. The Quick calculus software (online calculator for science) was used to determine t-statistic and $\mathrm{p}$-value of the untreated and various laser treated samples to be $\mathrm{p}<0.01$. It shows that those are statistically significant and the differences are quite meaningful, as to approve the use of EDX/WDX as a reliable tool for the species identification and subsequent analysis. The results of the modeling indicate that those are consistent with the experiments. Figure 7 depicts the variation of the significant alloying elements including $\mathrm{Mn}, \mathrm{Cr}, \mathrm{Ni}$ and $\mathrm{Fe}$ in the weld metal. It is seen that the concentrations of iron and nickel in the weld metal increase whereas the concentrations of the manganese and chromium decrease after the welding process.
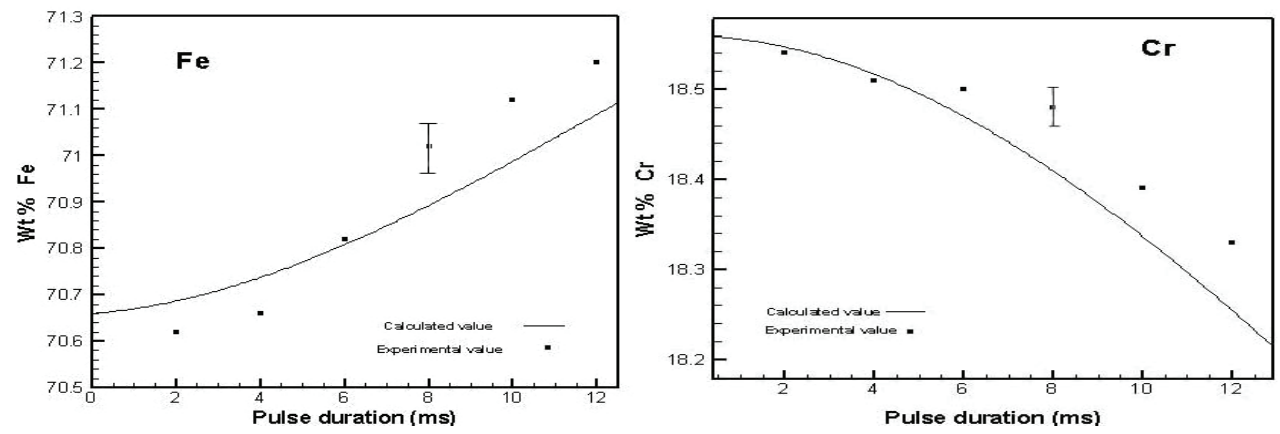

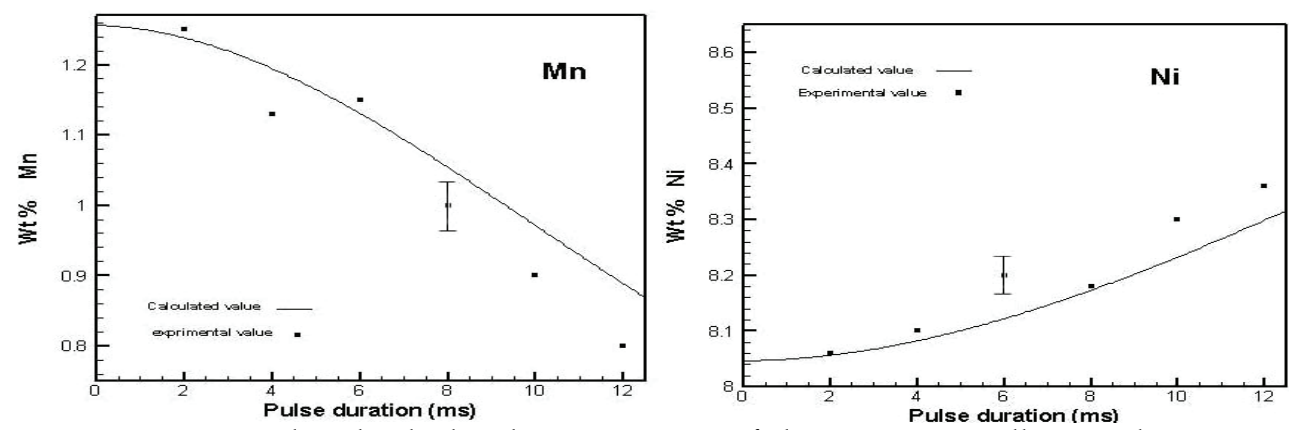

Fig. 7. Experimental and calculated concentration of the constituent alloying elements, as function of pulse duration for a power density of $12 \mathrm{GW} / \mathrm{m}^{2}$.

Although the total mass of iron and nickel in the weld pool is lower than those before the welding, the total mass of the weld pool has decreased at higher proportion because of the loss of manganese, chromium, iron, and nickel. As a result, the concentrations of iron and nickel in the fusion zone are higher than those in the base metal because of the loss of manganese and chromium.

The geometry of the keyhole including surface to volume of the weld pool were studied using data of section (3.1) in order to calculate the vaporization rate. The keyhole surface temperature was assumed to be the boiling temperature of the base metal due to the twophase characterizations of the keyhole surface during high power laser irradiation. It is believed that, both pressure and concentration gradients contribute to migrate the alloying elements outside the process area. The results obtained by the model show that the vaporization flux due to the pressure gradient is larger than that of the concentration gradient in the keyhole.

The vaporization mostly occurs not only at the surface of the keyhole but also in the region near the keyhole edge, where the temperature is taken close to the boiling point such that the vaporization out of this region is negligible corresponding to the concentration gradient (diffusion).

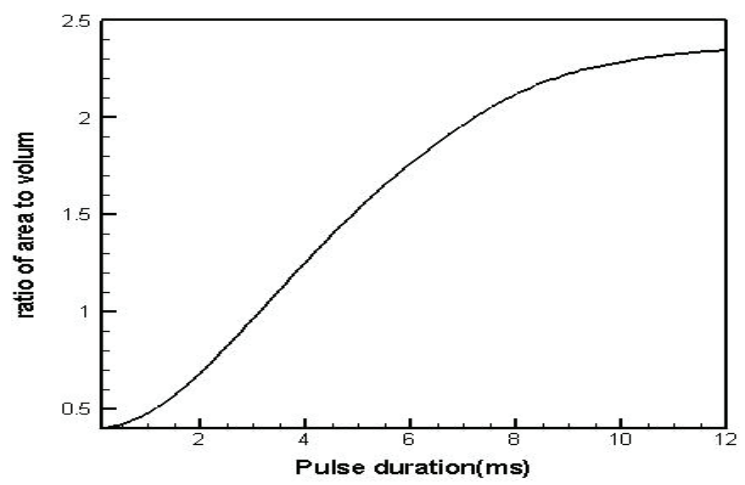

Fig. 8. Ratio of area to volume of the weld pool at end of pulse versus pulse duration for 12 $\mathrm{GW} / \mathrm{m}^{2}$ power Density 
According to the theory, the composition changes are mainly due to the volume and surface of the keyhole profile. Model shows that composition changes decrease with increase of the weld pool volume. The reduction of the keyhole surface causes to decrease in elements evaporation from the weld metal thus, a slight composition change happens. In other words, the keyhole area acts as sink and keyhole volume operates as source of alloying elements in the fusion zone. The pulse duration affects on the ratio of area to volume of the keyhole which is illustrated in figure 8 .

Figure 9 displays the spectra taken by EDX for the weld and base metal with $4 \mathrm{~ms}$ pulse duration and power density of $12 \mathrm{GW} / \mathrm{m}^{2}$. The respected picks of various elements show that the concentrations of $\mathrm{Mn}$ and $\mathrm{Cr}$ decrease in the weld metal while concentrations of $\mathrm{Fe}$ and $\mathrm{Ni}$ increase.
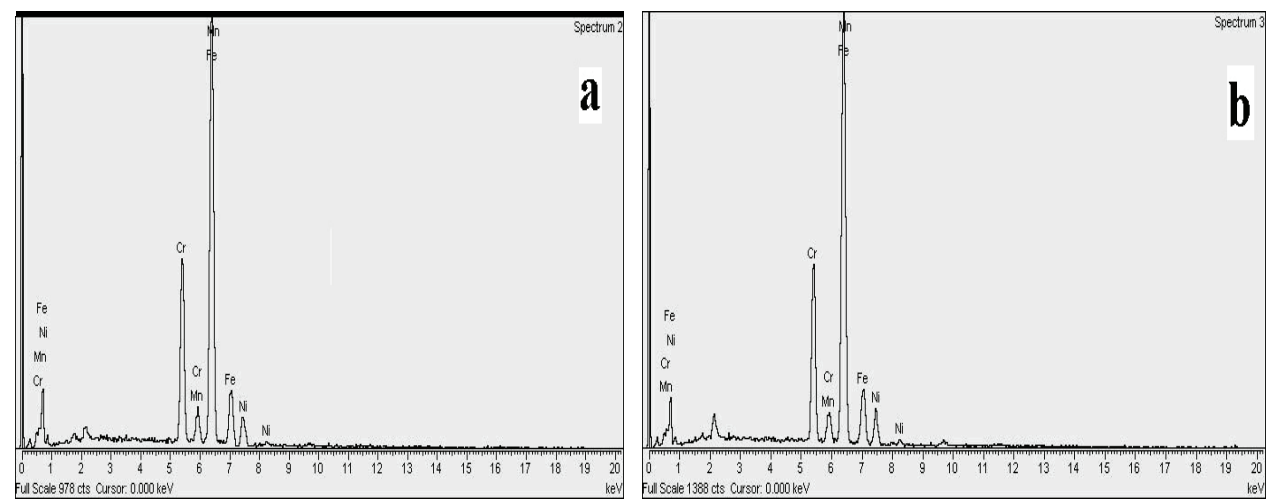

Fig. 9. EDX spectra of (a) base metal, (b) weld metal with power density of $12 \mathrm{GW} / \mathrm{m}^{2}$ and pulse duration of $4 \mathrm{~ms}$

Figure 10 illustrates the concentration profile of the constituent alloying elements using PIXE analysis. It obviously indicates that the manganese and chromium concentrations in the weld area decreases regarding the chemical composition of base metal.
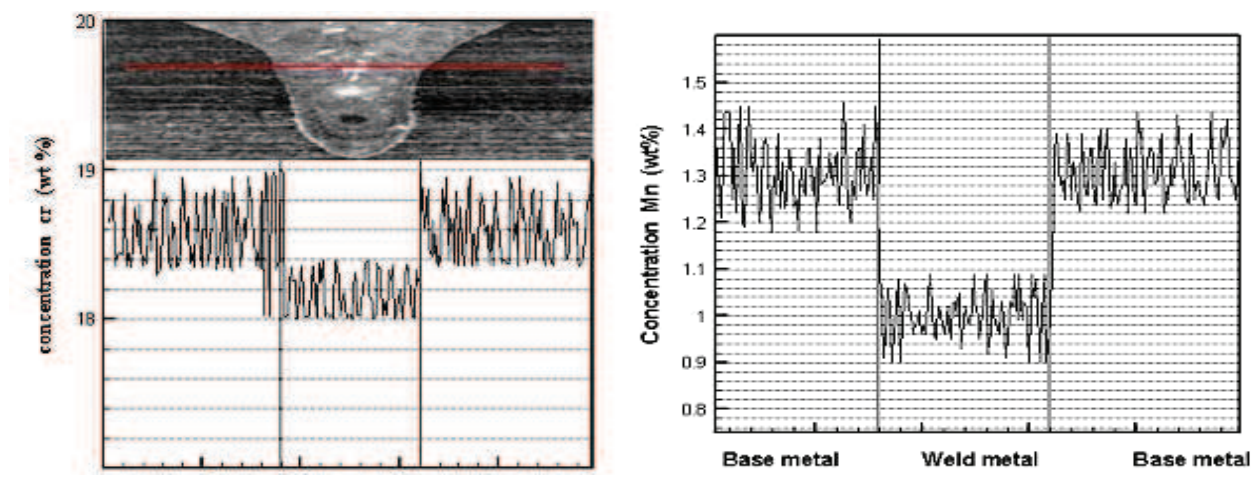

Fig. 10. Measured concentrations of $\mathrm{Cr}$ and $\mathrm{Mn}$ in the weld metal and surrounding base metal using PIXE. 
Similarly, the Mn and $\mathrm{Cr}$ densities in the weld metal for power densities of $10-20 \mathrm{GW} / \mathrm{m}^{2}$ were measured at constant pulse duration $(8 \mathrm{~ms})$ as shown in figure 11. It indicates that the concentration of manganese and chromium in the weld area decreases linearly versus increasing power density.

The influence of the laser power density on the ratio of the area to volume of the weld pool is depicted in figure 12. It is obvious that the ratio grows linearly with power density, leading to a linear reduction of $\mathrm{Mn}$ and $\mathrm{Cr}$ with power density mainly because the surface enlargement is dominant relative to volume growth, thus, the composition change significantly increases with laser power density. As the laser power density enhances, both the volume and surface of weld area enlarges, but area increase rate is greater than volume increase rate, thus, composition change in the weld pool increases with the laser power.
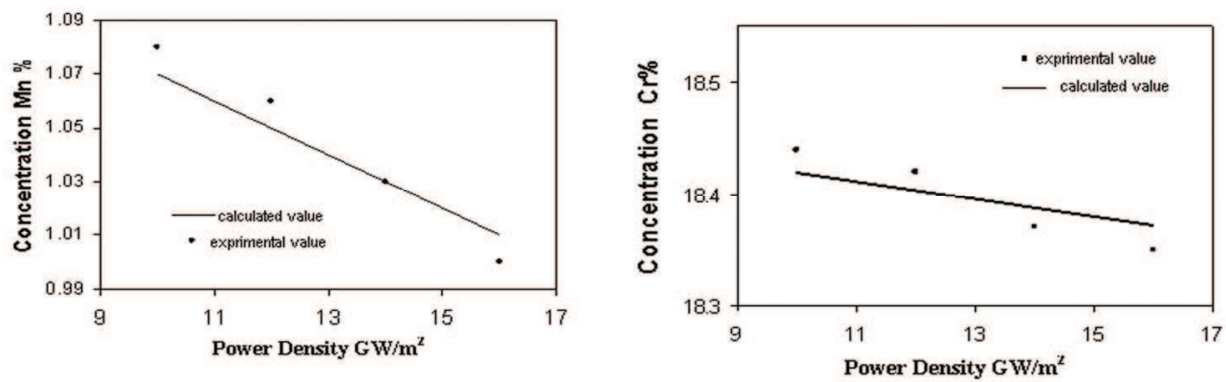

Fig. 11. Concentration of $\mathrm{Mn}$ and $\mathrm{Cr}$ in weld pool with different power density for $8 \mathrm{~ms}$ pulse durations.

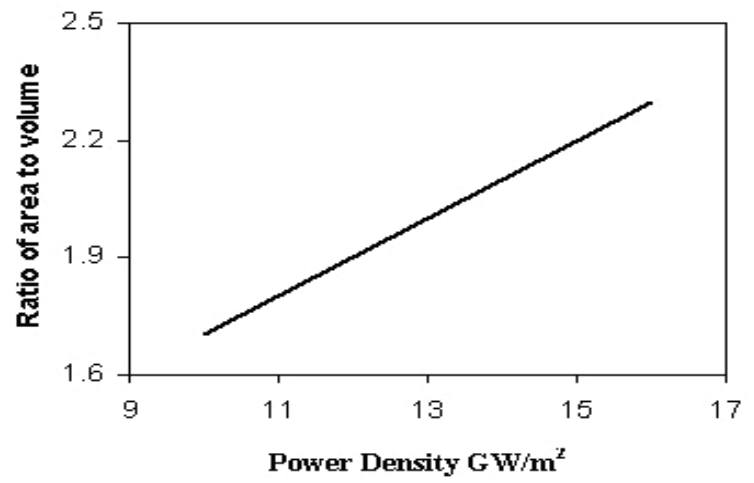

Fig. 12. Ratio of area to volume of the weld pool at end of pulse versus power density (pulse duration $=8 \mathrm{~ms}$ )

\section{Laser welding of Al5754}

\subsection{Laser welding set up}

The Specimens of aluminium alloy5754 were irradiated with a long pulsed Nd:YAG laser model IQL-10 with mean power of $400 \mathrm{~W}$ and standard square shaped pulses. The pulse energy of laser was varied from 4.5 to 10.5 joules while the pulse duration could be changed from 3 to $7 \mathrm{~ms}$ as well. The process speed $(9 \mathrm{~mm} / \mathrm{s})$ and the pulse repetition rate $(10 \mathrm{HZ})$ were 
kept to be invariant during the experiments. The details of the power measuring equipments, and optical focusing system are the same as mentioned in section 4.1. The welding work piece was a $2 \mathrm{~mm}$ thick aluminium alloy 5754 sheet metal such that the corresponding chemical composition is presented in table $4.10 \mathrm{lit} / \mathrm{min}$ flow of pure Ar gas, blowing from a coaxial nozzle was employed to shield the welding area against the oxidation.

\begin{tabular}{|l|llllllllllllllr|}
\hline Element & $\mathrm{Si}$ & $\mathrm{Mn}$ & $\mathrm{Cr}$ & $\mathrm{Ni}$ & $\mathrm{Fe}$ & $\mathrm{Mg}$ & $\mathrm{Sn}$ & $\mathrm{Bi}$ & $\mathrm{B}$ & $\mathrm{Co}$ & $\mathrm{Cu}$ & $\mathrm{Ga}$ & $\mathrm{Ti}$ & $\mathrm{V}$ & $\mathrm{Al}$ \\
\hline $\mathrm{Wt} \%$ & .12 & .25 & .08 & .006 & .37 & 3.009 & .002 & .004 & .0018 & .004 & .04 & .01 & .014 & .009 & balance \\
\hline
\end{tabular}

Table 4. Chemical composition of aluminun alloy 5754 .

\subsection{LIBS Set Up}

After welding processes, the concentrations of aluminum and magnesium in the weld and base meal were determined using LIBS analysis. Experimental set-up consists of conducting and focusing optics, laser pulse diagnostics, delay generator, spectrometer, and the processor as shown in Fig.13/1. An excimer laser (Lambda physics LPX200) with $40 \mathrm{~mJ} /$ pulse, 20ns duration, and pulse repetition rate of $1-10 \mathrm{~Hz}$, has been used as the coherent source at $193 \mathrm{~nm}$ to generate the micro plasma on the target surface. A couple of a quartz lens with 75 , and $150 \mathrm{~mm}$ focal lengths are situated in front of the main laser beam to increase the incident power density irradiating on the Al5754 samples. A semiconductor detector (PIN diode, EG\&G, FNT100), a 300-MHz digital storage Tektronix 30145, 2.5Gb/sec oscilloscope, as well as a 400-MHz Tektronix 7844 oscilloscope, and a Coherent TM joule / power meter (Field Master, LM-P10 \& LM-P5 100 heads) were used for the relative and absolute measurements of laser power and pulse energy.

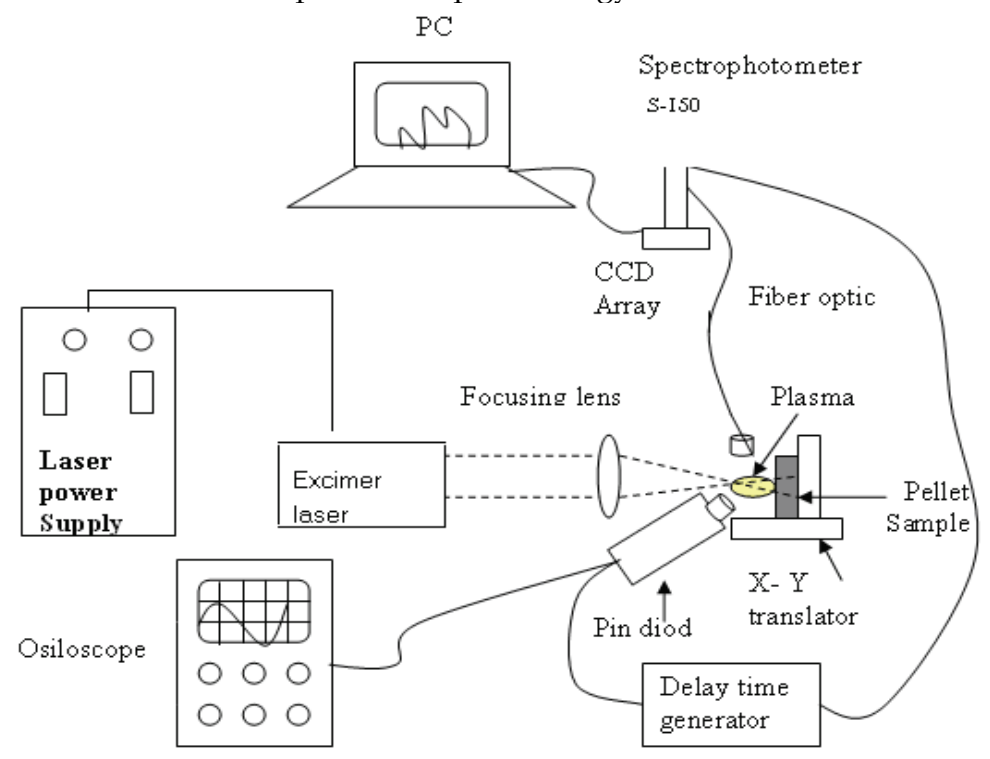

Fig. 13. LIBS set up using excimer laser. 
A fiber bundle (UV 600/660 type with SMA-905 fiber connector and 1m length) collected the light emission of the plasma using a quartz lens $(25 \mathrm{~mm}$ diameter, $50 \mathrm{~mm}$ focal length) placed $80 \mathrm{~mm}$ away from the sample. The fiber output was coupled to the entrance slit of a compact wide range spectrometer $(200-1100 \mathrm{~nm})$ model S150 Solar Laser Systems TM (50mm focal length, transmission diffraction grating with 200 grooves $/ \mathrm{mm}$ with $0.02 \mathrm{~mm} \times 3.0 \mathrm{~mm}$ of entrance slit and $0.5 \mathrm{~nm}$ spectral resolutions). A charge-coupled device (CCD) detector array model Toshiba TCD 1304AP with 3648 number of pixels was used to detect the dispersed light, subsequently. The CCD camera was triggered $\sim 2 \mu$ s after the onset of laser shot using a suitable delay generator in order to reduce the continuum Bremsstrahlung radiation.

\subsection{Calculation of the relative density of alloying elements using LIBS analysis}

Under LTE (local thermodynamic equilibrium) condition, the population of the exited levels for each species follows the Boltzmann distribution [9]:

$$
n_{i}^{s}=\frac{g_{i}}{U^{s}(T)} n^{s} e^{\frac{-E_{i}}{k T}}
$$

Where $n_{i}^{s}$ indicates the population density of the excited level i of species s, $n^{s}$ is the total number density of the species $\mathrm{s}$ in the plasma, $A_{i j}, E_{i}, g_{i}, \mathrm{~K}$, and $U^{S}(T)$ are the transition probability, the excitation energy of the level, the statistical weight for upper level, Boltzmann constant and the partition unction of the species at electronic temperature $\mathrm{T}$, respectively. The coefficients $A_{i j}$ and $g_{i}$ are taken from the National Institute for Standards and Technology (NIST), atomic spectra database [19].

$$
U^{s(T)}=\sum_{i} g_{i} e^{\frac{-E_{i}}{k T}}
$$

With the detectors typically used in the LIBS measurements, an alternative formula in terms of the integrated line intensity (number of transitions per unit volume per unit time) is preferred by:

$$
I_{i j}=n_{i}^{s} A_{i j}
$$

Now, by considering two lines, $\lambda_{i j}$ and $\lambda_{m n}$, of the same species, characterized by different values of the upper level energy $\left(E_{i} \neq E_{m}\right)$, the relative intensity ratio can be used to calculate the plasma temperature [9]

$$
T=\frac{E_{i}-E_{m}}{k \ln \left(\frac{I_{m n} g_{i} A_{j i}}{I_{i j} g_{m} A_{m n}}\right)}
$$

When selecting a line pair, it is advisable to choose two lines as close as possible in wavelength and as far apart as possible in excitation energy. This is to limit the effect of 
varying spectral response of the apparatus, as well as to minimize the sensitivity to small fluctuations in emission intensity.

To calculate the concentration ratios of the main components in the samples from the intensity ratios, it is desirable to compute the intensity ratio of two different lines from elements A and B. Concentration ratios of the elements A and B can derive from following equation:

$$
\frac{n^{A}}{n^{B}}=\frac{I_{i j} A_{m n} U^{A}(T) g_{m}}{I_{m n} A_{i j} U^{B}(T) g_{i}} \exp \left(\frac{-\left(E_{m}-E_{i)}\right.}{k T}\right)
$$

\subsection{Theoretical modeling}

A well-tested 'hydrodynamic' physical model described was used to simulate the keyhole profile as a function of time. The keyhole profile as a function of time was then used to calculate the vaporization rates of alloying elements. The data used for the keyhole formation during pulsed Nd:YAG laser welding of Al5754 [14] are presented in table 5.

\section{PROPERTY VALUE}

\begin{tabular}{ll}
\hline Density $\left(\mathrm{kg} / \mathrm{m}^{3}\right)$ & 2370 \\
Melting point $(\mathrm{K})$ & 933 \\
Boiling point $(\mathrm{K})$ & 2792 \\
Thermal conductivity of solid $\mathrm{W} / \mathrm{mK}$ & 237 \\
Effective viscosity $\left(\mathrm{kg} / \mathrm{m}^{5}\right)$ & 1.1 \\
Ratio of specific heats of vapor $\gamma_{v}$ & 1.667 \\
Beam radius $(\mu \mathrm{m})$ & 200 \\
Heat of evaporation of $(\mathrm{J} / \mathrm{mol})$ & 294000
\end{tabular}

Table 5. Date used for the keyhole formation during pulsed Nd:YAG laser welding of Al5754.

Close to the liquid phase, inside the keyhole on its walls, vaporization of material takes place within a sheath. The so-called Knudsen layer is governed by the transition from a nonequilibrium state at the keyhole wall to an equilibrium state a few mean free path distant from the liquid boundary. Vaporization of the alloying elements is due to the difference in partial vapor pressure and concentration gradient of each component. Pressure and concentration of alloying elements are higher near the weld pool surface in the Knudsen layer than in the bulk shielding gas and in the keyhole bulk [2-5,28] (In fact, the pressure of the vapor inside the keyhole is close to the ambient pressure [23]).

Partial pressure of each alloying element in the Knudsen layer is related to equilibrium temperature of this layer and can be calculated using the equation (14).Where A, B, C, D, 
and $\mathrm{E}$ are constant coefficients, which usually differs for the various elements, and $\mathrm{T}$ refers to the temperature. For the main elements of table 4 i.e. $\mathrm{Al}$, and $\mathrm{Mg}$, the corresponding coefficients are listed in table 6 [14].

\begin{tabular}{|l|l|l|l|l|l|}
\hline & A & B & C & D & E \\
\hline $\mathrm{Al}$ & 9.98 & $-1.38 \mathrm{E}+4$ & -.345 & $1.13 \mathrm{E}-11$ & $-1.21 \mathrm{E}-15$ \\
\hline $\mathrm{Mg}$ & -72.65 & $-4.201 \mathrm{E}+3$ & 30.26 & $-1.55 \mathrm{E}-2$ & $2.64 \mathrm{E}-6$ \\
\hline
\end{tabular}

Table 6. Constant coefficients required for calculation of equilibrium vapor pressure of $\mathrm{Al}$ and $\mathrm{Mg}$.

Total vapor pressure at the weld pool surface (Knudsen layer) is obtained from summation of the equilibrium vapor pressure of various alloying elements (equation 15).

It is suggested that Knudsen layer is filled only with metal vapor and no shielding gas attends inside. The calculated pressure of the Knudsen layer is subsequently used to obtain the loss of each alloying element due to concentration and pressure gradient vaporization rates.

\subsection{Comparison of theoretical and experimental results}

Several sets of aluminium alloy 5754 samples with $5 \mathrm{~cm} \times 5 \mathrm{~cm}$ area were cut and the welding process was done using laser pulses with $1500 \mathrm{~W}$ peak power and $3-7 \mathrm{~ms}$ durations. After welding, LIBS analysis was performed to study the constituents of the weld metal.

Emission spectra were taken from weld metal in atmospheric air employing a standard LIBS arrangement shown in figure13, using a UV ArF laser $(40 \mathrm{mj}, 10 \mathrm{~Hz}, 20 \mathrm{~ns}, 193 \mathrm{~nm})$ whose beam was focused through a quartz lens on the weld region of the solid sample. The collected light was launched into an optical fiber bundle coupled to the spectrometer, and recorded with an intensified charge coupled device (CCD) array.

In LIBS, the pulsed laser is initially focused on the target surface. The energies involved are in the $\mathrm{GW} \mathrm{cm}^{-2}$ range for the nanosecond duration, which are high enough to result in plasma formation through the subsequent process of vaporization, atomization and ionization in a single step. It leads to a high-temperature dense plasma that can be spectrally resolved and detected which contains the characteristic peaks with significant information on the nature and concentration of the elements. The integrated emission of the individual spectral lines, in principle, is associated with the number density of the corresponding emitting species in the plume. However, this, in turn, can be correlated with the element concentration in the sample, via the various calibration methods leading to the quantitative analysis. In general, it is desirable to increase the signal-to noise ratio $(\mathrm{S} / \mathrm{N})$ by scaling the strength of the signal for precision measurements of trace elements. The plasma characteristics are influenced by the laser-target interaction mechanisms including various laser properties such as wavelength, power density, laser pulse duration and energy.

LIBS analysis can be done using IR or UV laser exposure. The selective evaporation is the main mechanism, which becomes much more pronounced during IR laser irradiation of the target. The effect could be suppressed to a notable extent by UV laser exposure mainly due to the fact that absorption coefficient for the UV wavelength is considerably higher than IR 
[29]. Here, the emission spectra from the weld metal were taken using a UV excimer laser. It was shown that there was a good linear relation between the intensity of emission atomic spectral lines and the contents of alloying elements in samples. In fact, selective evaporation is not a dominant mechanism in UV laser. Therefore the plume concentration is nearly similar to that in the target during UV photo ablation. While using IR laser irradiation, the evaporation of the volatile elements alters the plume concentration from what is found in the target base. Figure 14 illustrates the typical LIBS spectrum obtained from weld metal. The selected lines are $\mathrm{Al}$ emission line at $396.1 \mathrm{~nm}$ and the $\mathrm{Mg}$ characteristic line at $285.2 \mathrm{~nm}$ that are shown more clearly in figure 14(b) for welding condition with various pulse durations. In fact, a proper delay time is required to eliminate the continuum spectrum as the background noise that mostly arises from the ion recombination with free electrons. The strong emission characteristic lines due to dominant neutral $\mathrm{Al}$ and $\mathrm{Mg}$ trace were used to determine the relative density $\left(\frac{n_{A l}}{n_{M g}}\right)$ subsequently.

Reliability was examined through mean and relative standard deviation (\%RSD) of each set of experimental data taken from LIBS repeated measurements.

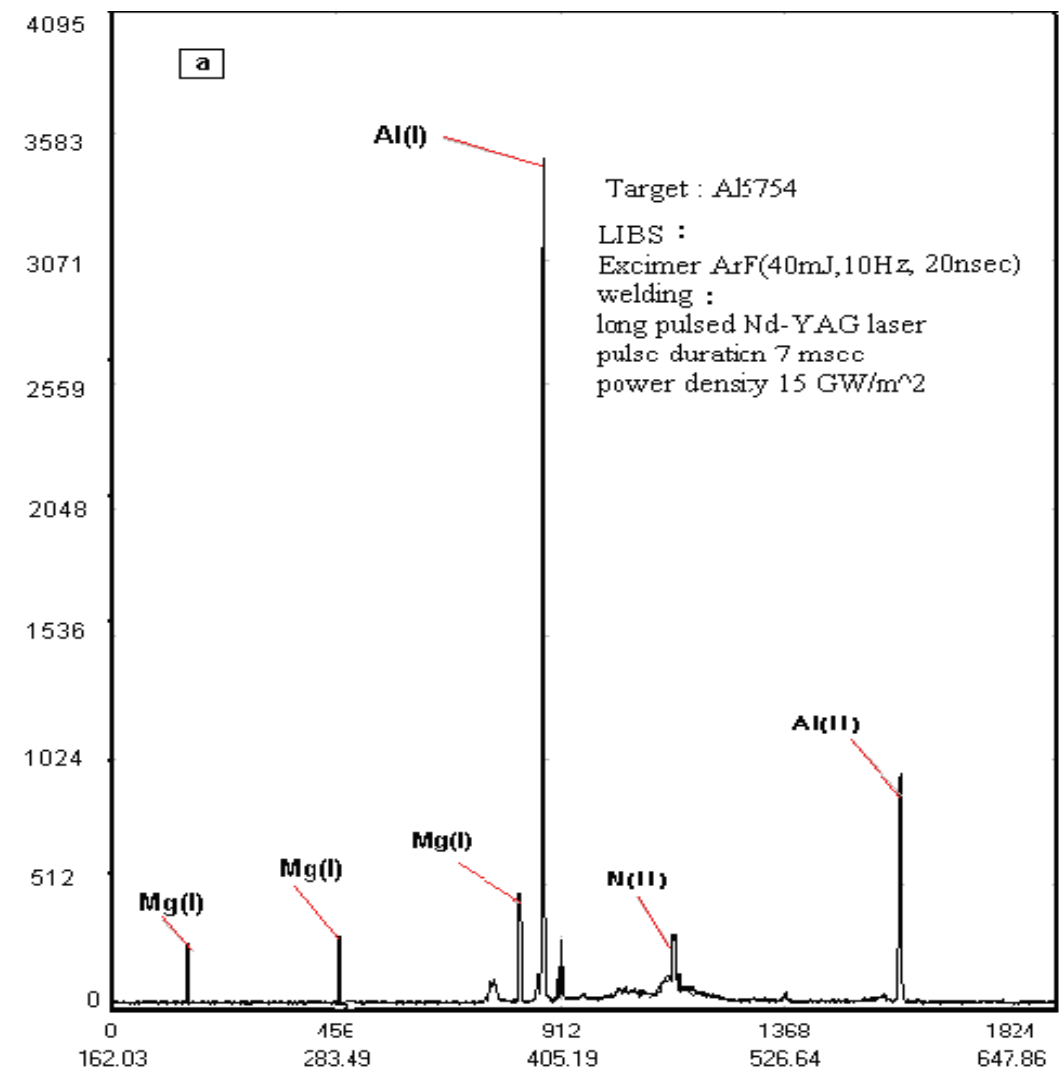




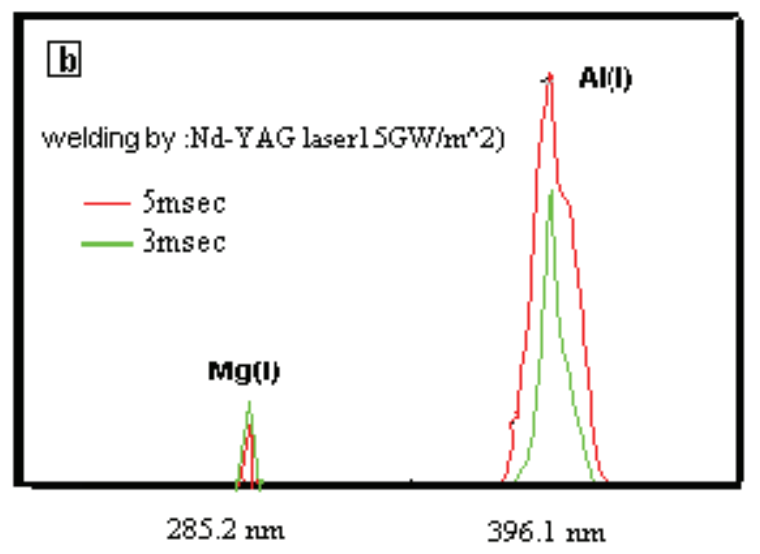

Fig. 14. (a)A typical spectrum of weld metal Al5754 using a long pulse Nd:YAG with 7ms pulse duration and $15 \mathrm{Gw} / \mathrm{m}^{2}$ power density (b) the emission characteristic lines of $\mathrm{Al}$ (396.1 $\mathrm{nm})$ and $\mathrm{Mg}(285.2 \mathrm{~nm})$ for laser welding with different pulse duration (3and $5 \mathrm{msec}$ )

Mean Intensities of $\mathrm{Al}$ and $\mathrm{Mg}$ emission lines for various conditions of the laser welding process (3-7msec pulse duration) are revealed in table 7.

\begin{tabular}{|l|l|l|l|l|l|}
\hline Pulse duration of laser welding process & $3 \mathrm{msec}$ & $4 \mathrm{msec}$ & $5 \mathrm{msec}$ & $6 \mathrm{msec}$ & $7 \mathrm{msec}$ \\
\hline mean Intensity $(285.2 \mathrm{~nm}, \mathrm{MgI})$ & 211 & 202 & 197 & 193 & 190 \\
\hline$\%$ RSD $(285.2 \mathrm{~nm}, \mathrm{MgI})$ & 2 & 1.3 & 1.5 & 2.2 & 1.9 \\
\hline mean Intensity (396.1 $\mathrm{nm}, \mathrm{AlI})$ & 2563 & 2993 & 3021 & 3205 & 3421 \\
\hline$\%$ RSD $(396.1 \mathrm{~nm}, \mathrm{AlI})$ & 1.9 & 1.8 & 2.1 & 2.2 & 1.9 \\
\hline
\end{tabular}

Table 7. Mean Intensities of $\mathrm{Al}$ and $\mathrm{Mg}$ emission lines in LIBS analysis for 3-7msec pulse durations of laser welding

The generated plasma in the laser ablation process is assumed to be in local thermodynamic equilibrium (LTE). The LTE condition is given by [30]:

$$
N_{e} \geq 1.6 \times 10^{12} T^{1 / 2} \Delta E^{3}
$$

Where $N_{e}$ ascertains the electron density, $T(K)$ denotes the plasma temperature, and $\Delta E(e V)$ is the largest energy transition for which the condition holds. Electron density is known as an important plasma parameter, which gives indications about the thermal equilibrium. A common method for spectroscopic determination of $N_{e}$ is based on the Stark effect of the atomic or ionic lines whereas for typical LIBS, the contribution of ion broadening could be negligible. Therefore, the Stark broadening $\Delta \lambda_{s}$ of the neutral line expressed as the FWHM in nanometers is simplified as $[13,31]$ : 


$$
\Delta \lambda_{s}=2 W\left(\frac{N_{e}}{10^{16}}\right)
$$

Where $\mathrm{W}$ is the electron impact parameter.

Therefore, the line width $\Delta \lambda_{s}$ corresponding to the typical characteristic NII line was determined to estimate the electron density. The experiment satisfies equation (36) to emphasize the validity of LTE condition. Thus, Boltzmann equation is used to relate the population of an excited level to the number density of the species within the plasma. The typical electron density and temperature were determined to be $\sim 10^{18} \mathrm{~cm}^{-3}$ and $\sim 10^{4} \mathrm{~K}$ respectively. It is notable to mention that emission line of NII at $500.5 \mathrm{~nm}$ is an intense line with the stark broadening of about $5 \mathrm{~nm}$ that is one order of magnitude greater than the optical resolution of the spectrometer $(0.5 \mathrm{~nm})$ and concludes to an acceptable accuracy in determination of $\mathrm{N}_{\mathrm{e}}$.

Because the transitions are element specific and quantized or of a specific wavelength, a given species has the highest probability of reabsorbing a photon emitted by a member of the same species. Because of the high density of atoms in the micro plasma and its characteristically high temperature and electron density gradients, cool atoms, residing mostly in the ground state, will populate the outer layer of the plasma. The central core of the plasma will contain a higher density of excited atoms. As these atoms decay to the ground state, the emitted photons corresponding to resonance transitions will have a high probability of being absorbed by the cooler atoms in the outer layers, thereby reducing the observed intensity of the emission line. As the concentration of the atoms in the target sample increases, the number of cooler atoms in the outer layer increases and selfabsorption becomes evident [8]. Consequently in quantitative laser induced breakdown spectroscopy it is essential to account for the effect of self-absorption on the emission lines intensity.

The self-absorption coefficient (SA) is defined as the ratio of the measured height peak to the value of the line peak in absence of self-absorption. It is clear that, in the presence of Self absorption, the intensity of the line at its maximum (i.e. for $\lambda=\lambda_{0}$ ) is lower than in optically thin condition, according to the following relation [32]:

$$
\frac{I\left(\lambda_{0}\right)}{I_{0}\left(\lambda_{0}\right)}=S A
$$

$I_{0}\left(\lambda_{0}\right)$ represents the line profile assuming negligible self-absorption. In turn, the knowledge of the coefficient (SA) allows correcting the peak line intensity. (SA) is equal to one if the line is optically thin, while it decreases to zero as the line becomes optically thick. Self-absorption coefficient is easily derived, using equation (39).

$$
(S A)=\left(\frac{10^{16} \Delta \lambda}{2 W N_{e}}\right)^{-0.5}
$$

Where $\Delta \lambda$ is line width that is directly obtained from the spectrum analysis and $\mathrm{W}$ parameter of the regarded line is obtained from relevant literatures $[32,33]$. 
Self-absorption coefficients SA were evaluated for emission characteristic line of neutral Al at $(396.1 \mathrm{~nm})$ and neutral $\mathrm{Mg}$ at $(285.2 \mathrm{~nm})$ in order to correct relative density of $\mathrm{Al}$ to $\mathrm{Mg}$. Figure 15 depicts the ratio of relative concentration of alloying elements in the weld metal as a function of the welding laser pulse duration. It is seen that the ratio of aluminium to magnesium concentrations linearly increases in terms of pulse duration. In other words, magnesium concentration in the weld metal decreases, whereas the aluminium concentration increases simultaneously. It indicates that $\mathrm{Mg}$ loss significantly increases with longer pulses.

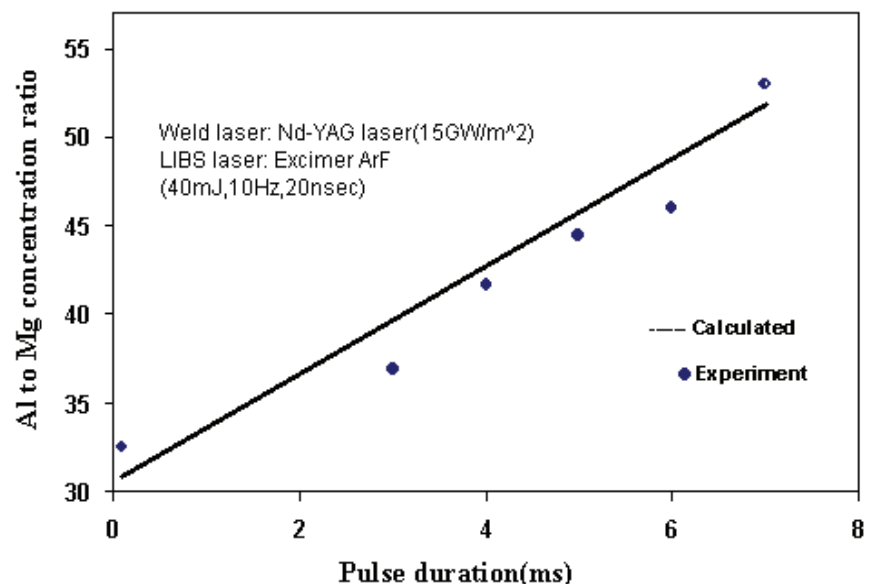

Fig. 15. Ratio of aluminium to magnesium concentrations as a function of pulse duration in Nd:YAG laser welding.

The geometry of the keyhole, i.e. surface to volume of the weld pool, is required to estimate the vaporization rate that was investigated in our previous work exhaustively. Therefore, surface and volume of the keyhole are essentially taken into account as a couple of significant parameters for the element loss measurement. The keyhole area acts as sink and its volume functions as a source of alloying elements within the fusion zone. The reduction of the keyhole surface causes to decrease of the element evaporation leading to smaller loss of element such that, a slight change in the composition occurs. In fact, the pulse duration strongly affects on the ratio of area to volume of the keyhole as displayed in figure 16.

Computational results indicate that ratio of area to volume increases with pulse duration of a single shot accompanied by an increase of the vaporization rate. The element loss becomes more significant during long pulsed welding accordingly.

The keyhole surface temperature was assumed to be kept at the boiling temperature of the base metal due to two-phase characterization of the keyhole surface during high power laser irradiation. The model shows that the vaporization flux due to the pressure gradient is larger than the vaporization flux due to the concentration gradient in the keyhole.

The influence of the laser power density on the ratio of keyhole area to volume as well as the ratio of aluminum to magnesium concentrations in the weld pool are shown in figure17(a,b). Figure 17(a) illustrates that the ratio of keyhole area to volume is kept nearly invariant for a wide range of power densities to indicate that is not very sensitive to variation of laser power. In addition, figure $17(\mathrm{~b})$ displays that, the ratio of the relative concentrations of 
magnesium and aluminum within the weld metal are independent of the laser power density. This fact was inferred from the model and confirmed by the experimental data obtained from LIBS analysis.

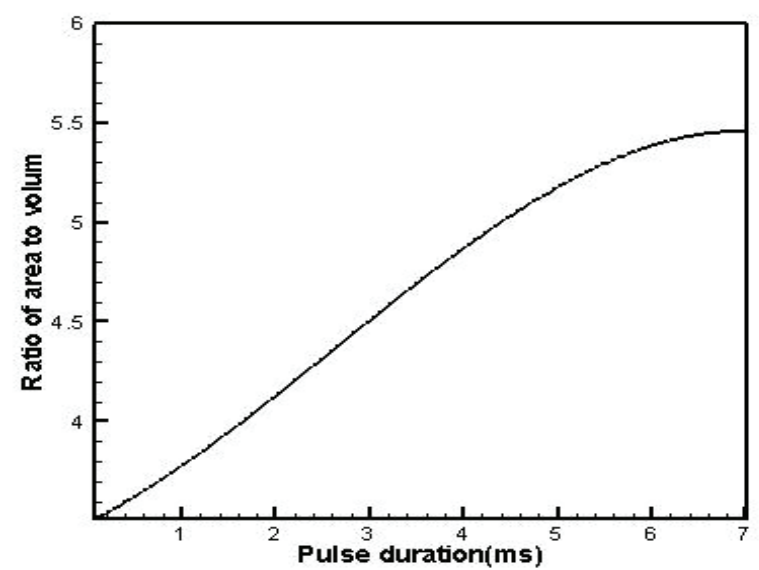

Fig.16. Ratio of keyhole area to volume of the weld pool at the end of a single pulse for various pulse durations at $15 \mathrm{GW} / \mathrm{m}^{2}$ power density
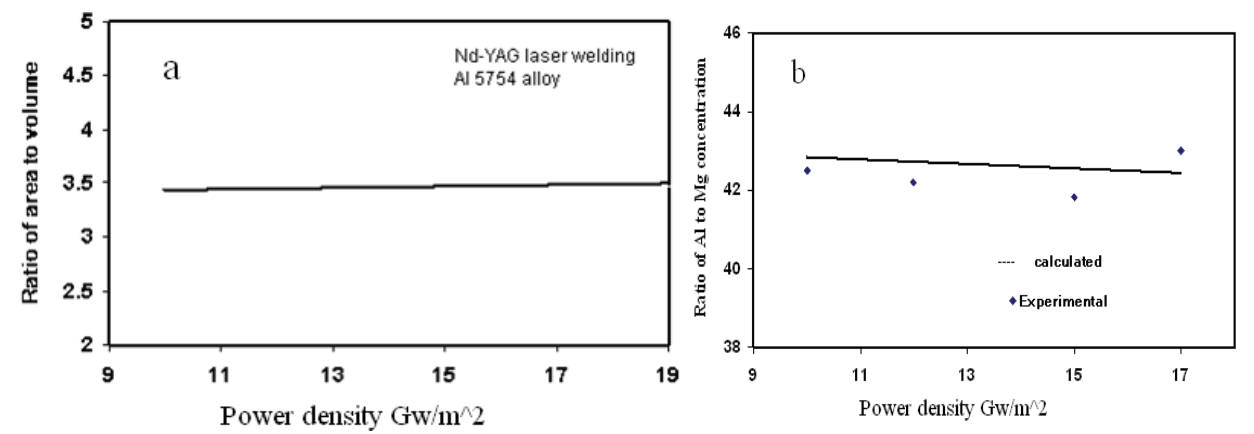

Fig. 17. (a) The ratio of keyhole area to volume, and (b) ratio of aluminium to magnesium concentrations versus laser power density.

\section{Conclusion}

Here, we have shown that the alloying elements are controlled in the weld metal by changing the laser parameters in the keyhole welding of SS316 and Al5754 using a long pulsed Nd:YAG laser. Śeveral experiments were performed and a theoretical model was developed for the determination of significant alloying element losses such as $\mathrm{Mn}, \mathrm{Cr}, \mathrm{Ni}$, and $\mathrm{Fe}$ in SS316 and $\mathrm{Al}$ and $\mathrm{Mg}$ in Al5754. Despite laser welding is a complicated process, here, the effect of laser parameters (mainly for various pulse duration at constant power density, as well as the different power densities at the invariant pulse duration.) were investigated on the composition alteration of the weld metal.

Based on the analysis and modeling, we have shown that in SS316 welding the Mn, Cr concentrations reduce within the weld metal however, those of $\mathrm{Fe}$, $\mathrm{Ni}$ increase 
simultaneously, mainly due to the higher equilibrium pressure of $\mathrm{Mn}$ and $\mathrm{Cr}$ respect to $\mathrm{Fe}$ and $\mathrm{Ni}$ according to figure 4 [34].

In fact, a couple of competitive mechanisms are involved including keyhole shape (surface to volume ratio) and the diffusion time of the migrated elements. The concentrations of alloying elements are nonlinear in terms of the laser pulse duration due to the nonlinearity of surface to volume ratio versus the pulse duration. It was found that the keyhole shape is significant for shorter pulse duration; however, the diffusion time becomes dominant at longer pulses according to figures 8 and 16 .

Moreover, when power density varies from $10 \mathrm{GW} / \mathrm{m}^{2}$ to $20 \mathrm{GW} / \mathrm{m}^{2}$ while the laser pulse duration is kept unchanged, then the element loss increases linearly mainly due to the linear correlation of surface to volume ratio with peak power density.

Elemental change of Al5754 alloy after laser welding was extensively investigated using LIBS technique for element tracing in the weld metal [35]. ArF laser was employed to create micro plasma over the weld region. The LIBS analysis includes the significant finding as below:

i) $\mathrm{Mg}$ loss linearly increases with increasing the pulse duration of the laser welding.

ii) The variation of $\mathrm{Mg}$ trace is negligible while varying the laser power density.

Moreover, the ratio of keyhole area to volume strongly depends on the pulse duration which is in good agreement to the above conclusion (i).

Finally the keyhole geometry obtained from model remains invariant with the laser power density of pulsed Nd:YAG laser source which is in accordance with the above conclusion (ii). Eventually in order to increase the welding depth, it is suggested to increase the laser power densities rather than using longer pulse durations to assure of minimum $\mathrm{Mg}$ loss.

\section{Appendix}

The mass diffusivity of an element $a$ in the shielding gas $b$ at temperature $T$ is given by [2]

$$
\begin{gathered}
D_{a b}=\frac{1.8583 \times 10^{-7} \sqrt{\frac{M_{b}+M_{a}}{M_{b} M_{a}}}}{\sigma_{a b}^{2} \Omega\left(\frac{K T}{\varepsilon}\right)} T^{\frac{3}{2}} \\
\sigma_{a b}=\frac{\sigma_{a}+\sigma_{b}}{2}
\end{gathered}
$$

Where $\sigma$ the collision diameter in angstroms, $\mathrm{M}$ is molecular weight, and $\Omega$ is the slowly varying function of the parameter $\frac{K T}{\varepsilon}$ which is given by:

$$
\Omega=\left(44.45\left(\frac{K_{B} T}{\left(\varepsilon_{a} \varepsilon_{b}\right)^{\frac{1}{2}}}\right)^{-4.909}+1.911\left(\frac{K_{B} T}{\left(\varepsilon_{a} \varepsilon_{b}\right)^{\frac{1}{2}}}\right)^{-1.575}\right)^{0.1}
$$

Where $\varepsilon$ refers to the intermolecular force parameter. 


\section{References}

1. A. Block-Bolten and T. W. Eagar: Metallurgical Transaction B, 15B, 461, 1984

2. K. Mundra and T. Debroy: Metallurgical Transaction B, 24B, 145, 1993

3. H. Zhao and T. Debroy: Metallurgical Transaction B, 32B, 163, 2001

4. P.A.A. Khan, T. Debroy, and S.A. David: Metallurgical Transaction B, 67, pp.1s-7s, 1988

5. X. He and T. Debroy: J. Phys. D: Applied Physics, 37, 4547, 2004

6. M.J. Torkamany, M.J. Hamedi, F. Malek, and J. Sabbaghzadeh: J. Phys. D: Applied Physics, 39, 4563, 2006

7. U. Dilthey, A. Goumeniouk, V. Lopota, G. Turichin and E. Valdaitseva: J. Phys. D: Applied Physics, 34, 81, 2001

8.David A. Cremers, Leon J. Radziemski .Handbook of Laser-Induced Breakdown Spectroscopy, 2006 (John Wiley\&Sons,Ltd)

9. Anderzej W. Miziolek, Vincenzo Palleschi, Israel Schechter. Laser-Induced Breakdown Spectroscopy, 2006 (CAMBRIDGE University press)

10. D. A. Rusak, B .C .Castle, B .W .Smith, J .D. Winfordner; Crit. Rev. Anal.Chem., Vol. 27, pp 257, 1997

11. P. Lucena and J. J. Laserna; Spectrochim. Acta B, Vol.56, pp. 1120, 2001

12. L. Barrette and S. Turmel; Spectrochim. Acta B, Vol. 56, pp. 715, 2001

13. S. Z. Shoursheini, P. Parvin, B. Sajad, M. A. Bassam; Applied spectroscopy, Vol. 63, P.423-9, 2009

14. Jae Y. Lee, Sung H. Ko, Dave F. Farson and Choong D. Yoo; J. Phys. D: Applied Physics, 35, 1570, 2002

15. Xi Chenl and Hai-Xing Wang; J. Phys. D: Applied Physics, 36, 1634, 2003

16. A Matsunawa and V Semak; J. Phys. D: Applied Physics, 30, 798, 1997

17. W.W. Duley: laser welding (New York: Wiley), 1998

18. Conny Lampa, Alexander F. H. Kaplan, John Powell, and Claes Magnusson; J. Phys. D: Applied Physics, 30, 1293, 1997

19. T. Zacharia, S.A. David, J.M. Vitek and T. Debroy; Welding Journal, 12, 499, 1989

20. W. Sudnik, W. Erofeev and D. Radaj; J. Phys. D: Applied Physics, 29, 2811, 1996

21. E. Amara and A. Bendib; J. Phys. D: Applied Physics, 35, 272, 2002

22. J. Sabbaghzadeh, S. Dadras, and M.J. Torkamany; Journal of Physics D: Applied Physics, 40, 1047, 2007

23. V. Vladimir, W.D. Semak, B. Bragg, Damkroger and S Kempka; J. Phys. D: Applied Physics, 32, L61-L64, 1999

24. W. Robert, Jr. Messler: "Principles of welding"; (WILY-VCH Publishing Co.), 2004

25. C.L.Yaws, Handbook of vapor pressures (Gulf Publishing Co., Houston), 1994

26. S. Dusham and J.M. Laferty; Scientific foundations of vacuum technique, $2^{\text {nd }}$ edition, John wily, New York, PP.691-737, 1962

27. E.U. Schlunder and V. Gniclinski; Chem. Eng. Technology, 39, 578, 1967

28. O. Solana and J. L. Ocana; J. Phys. D: Applied Physics, 30, 1300, 1997

29. H. Kurniawan, A. N. Chumakov, Tjung Jie Lie, M. O. Tjia, M. Ueda, and K. Kagawae; Journal of Applied Spectroscopy, Vol. 71, pp.5-9, 2004

30. A.W. Miziolek, V. Palleschi, I. Schechter, Laser Induced Plasma Spectroscopy, 2006, (Cambridge: Cambridge University Press) chapter 3, 122pp

31. H. R. Griem, Spectral line broadening by plasma (Academic Press, 1974), Appendix. 4, pp. 320. 
32. A.M. El Sherbini, Th.M. El Sherbini, H. Hegazy, G. Cristoforetti, S. Legnaioli, V. Palleschi, L. Pardini, A. Salvetti, E. Tognoni; Spectrochimica Acta Part B, Vol. 60, pp. 1573 - 1579, 2005

33. H.R. Griem, Plasma Spectroscopy, Mc Graw Hill, New York, 1964.

34. M. Jandaghi, P. Parvin, M. J. Torkamany, J. Sabbaghzadeh; Journal of Physics D: Applied Physics, Vol. 41(23) 235503 (9pp) (2008)

35. M. Jandaghi, P. Parvin, M. J. Torkamany, J. Sabbaghzadeh; Journal of Physics D: Applied Physics, Vol. 42(20) 205301 (8pp) (2009) 


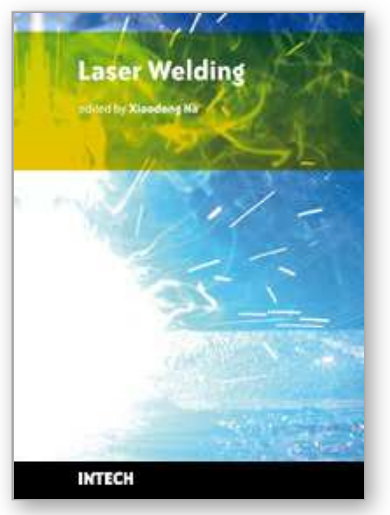

\author{
Laser Welding \\ Edited by Xiaodong $\mathrm{Na}$, Stone
}

ISBN 978-953-307-129-9

Hard cover, 240 pages

Publisher Sciyo

Published online 17, August, 2010

Published in print edition August, 2010

This book is entitled to laser welding processes. The objective is to introduce relatively established methodologies and techniques which have been studied, developed and applied either in industries or researches. State-of-the art developments aimed at improving or next generation technologies will be presented covering topics such as monitoring, modelling, control, and industrial application. This book is to provide effective solutions to various applications for field engineers and researchers who are interested in laser material processing.

\title{
How to reference
}

In order to correctly reference this scholarly work, feel free to copy and paste the following:

Mohammad Javad Torkamany, Parviz Parvin, Maryam Jandaghi and Jamshid Sabbaghzadeh (2010). Estimation of Composition Change in Pulsed Nd:YAG Laser Welding, Laser Welding, Xiaodong Na, Stone (Ed.), ISBN: 978-953-307-129-9, InTech, Available from: http://www.intechopen.com/books/laserwelding/estimation-of-composition-change-in-pulsed-nd-yag-laser-welding-

\section{INTECH}

open science | open minds

\section{InTech Europe}

University Campus STeP Ri

Slavka Krautzeka 83/A

51000 Rijeka, Croatia

Phone: +385 (51) 770447

Fax: +385 (51) 686166

www.intechopen.com

\section{InTech China}

Unit 405, Office Block, Hotel Equatorial Shanghai

No.65, Yan An Road (West), Shanghai, 200040, China

中国上海市延安西路65号上海国际贵都大饭店办公楼405单元

Phone: +86-21-62489820

Fax: +86-21-62489821 
(C) 2010 The Author(s). Licensee IntechOpen. This chapter is distributed under the terms of the Creative Commons Attribution-NonCommercialShareAlike-3.0 License, which permits use, distribution and reproduction for non-commercial purposes, provided the original is properly cited and derivative works building on this content are distributed under the same license. 